\title{
HUBUNGAN SELF EFFICACY DENGAN KECEMASAN PENDERITA GAGAL GINJAL KRONIK YANG MENJALANI HEMODIALISA DI RSUD JOMBANG
}

\author{
CORRELATION OF SELF EFFICACY WITH ANXIETY ON CHRONIC RENAL FAILURE \\ PATIENTS UNDERGOING HEMODIALYSIS IN THE JOMBANG PUBLIC HOSPITAL
}

\author{
Uswatun hasanah $^{1)}$, Heni Maryati $^{2)}{ }^{2}$ Pepin Nahariani ${ }^{3)}$ \\ ${ }^{1,3}$ Progam Studi S1 Keperawatan STIKES Pemkab Jombang \\ ${ }^{2}$ Progam Studi D3 Keperawatan STIKES Pemkab Jombang \\ email : nie.maryati@gmail.com hp.081335701857
}

\begin{abstract}
Chronic kidney disease is irreversible, meaning there could be normal again, who could do is maintain existing renal function undergoing dialysis treatment throughout their lives (usually 1-3 times a week) or to get a new kidney through a kidney transplant operation. It can lead to psychological disorders such as anxiety. With Anxiety will exacerbate the perceived disease. One of the factors that influence anxiety is self-efficacy. This research aims to determine the correlation of self-efficacy with the level of anxiety in patients with chronic renal failure undergoing hemodialysis in Jombang Public Hospitals. This research is a correlation analytic method with cross sectional approach. In this research population of 33 respondents include all patients with chronic renal failure undergoing hemodialysis in Jombang Public Hospitals first time - 6 months. A sample of 30 respondents were taken using accidental sampling. The independent variable was self-efficacy, the dependent variable anxiety, how to collect data by statistical tests used questioner Spearman's rank. The research was conducted on 24-31 May 2016. The statistical test used in this study was Spearman's rank correlation. Based on the results of research in Hemodialysis room Jombang Public Hospitals found that half (50\%) of respondents have a positive self-efficacy and nearly half (36.7\%) of respondents are not anxiety. Statistical test results showed significancy value of $0.001(p<0.05)$. It was indicated that there was a correlation of self-efficacy with the level of anxiety in patients with chronic renal failure undergoing hemodialysis in the hemodialysis room Jombang Public Hospitals in 2016.Need to improve services through counseling, information and education on management of chronic renal failure and can provide knowledge about self efficacy other than that can involve the family in supporting the implementation of self-efficacy.
\end{abstract}

Keywords: Self Efficacy, Anxiety, Chronic Renal Failure, Hemodialysis.

Abstrak: Penyakit ginjal kronis bersifat irreversible, artinya tidak bisa menjadi normal kembali, yang bisa dilakukan hanyalah mempertahankan fungsi ginjal yang ada dengan menjalani terapi dialysis sepanjang hidupnya (biasanya 1-3 kali seminggu) atau sampai mendapat ginjal baru melalui operasi pencangkokan ginjal. Hal ini dapat mengakibatkan gangguan psikologis seperti kecemasan. Dengan cemas akan memperparah penyakit yang dirasakan. Salah satu faktor yang mempengaruhi kecemasan adalah dengan self efficacy. Penelitian ini bertujuan untuk mengetahui adanya hubungan self efficacy dengan tingkat 
kecemasan pada pasien gagal ginjal kronik yang sedang menjalani hemodialisa di RSUD Jombang.Jenis penelitian ini adalah metode analitik korelasi dengan pendekatan cross sectional. Pada penelitian ini populasi sejumlah 33 responden mencakup seluruh pasien gagal ginjal kronik yang sedang menjalani hemodialisa di RSUD Jombang pertama kali - 6 bulan. Sampel sejumlah 30 responden diambil menggunakan Accidental Sampling. Variabel independen adalah self efficacy, variabel dependen Kecemasan, cara pengambilan data dengan koesioner uji statistic yang dipakai spearman's rank. Berdasarkan hasil penelitian yang telah dilakukan pada tanggal 24-31 Mei 2016, didapat bahwa setengah (50\%) responden memiliki self efficacy positif dan hampir setengah $(36,7 \%)$ responden tidak cemas. Hasil uji statistic menunjukkan nilai signifikansi $\mathrm{p}$ value $=0,001$ yang berarti ada hubunganself efficacy dengan tingkat kecemasan pada penderita gagal ginjal kronik yang sedang menjalani hemodialisa di ruang hemodialisa RSUD Jombang tahun 2016. Petugas kesehatan perlu meningkatkan pelayanan melalui konseling, informasi dan edukasi tentang penatalaksanaan gagal ginjal kronik dan dapat memberikan pengetahuan tentang self efficacy selain itu dapat melibatkan keluarga dalam mendukung penerapan self efficacy.

Kata kunci : Self Efficacy, Kecemasan, Gagal Ginjal Kronik, Hemodialisa.

\section{PENDAHULUAN}

Beberapa tahun belakangan telah terjadi perubahan pola penyakit di Indonesia, antara lain dengan meningkatnya tren penyakit katastropik setiap tahun. Penyakit katastropik, merupakan penyakit berbiaya tinggi dan secara komplikasi dapat membahayakan jiwa penderitanya, antara lain : penyakit ginjal, penyakit jantung, penyakit syaraf, kanker, diabetes mellitus, dan haemofilia. Mengutip data sebaran kasus dan biaya klaim di Rawat Jalan Tingkat Lanjut (RJTL) Badan Penyelenggara Jaminan Sosial (BPJS) Kesehatan sampai dengan triwulan III tahun 2015, kasus sistem saluran kemih berjumlah sebanyak 3.094.915 urutan tertinggi ketiga, namun menghabiskan biaya lebih dari 3 Trilyun rupiah (Riskesdas,2016). Penyakit ginjal kronik merupakan salah satu masalah utama kesehatan di dunia. Prevalensi Penyakit gagal ginjal kronis selama sepuluh tahun terakhir semakin meningkat. Saat ini, meningkatnya lebih dari $50 \%$ pada tahun 2010. Tanpa pengendalian yang cepat dan tepat pada tahun 2015 penyakit ginjal diperkirakan bisa menyebabkan kematian hingga 36 juta penduduk dunia. Menurut United State Renal Data System (USRDS) di Amerika Serikat prevalensi penyakit gagal ginjal kronis meningkat sebesar $20-25 \%$ setiap tahunnya (Putra, 2013).

Pada tahun 2011 ke 2012 terjadi peningkatan bertambah 880 orang menjadi 24.141 pasien. Menurut data dari Riset Kesehatan Dasar (Riskesdas) tahun 2013 prevalensi gagal ginjal kronik di Indonesia sekitar 0,2\%. Yagina (2014) mengemukakan angka dunia secara global lebih dari 500 juta orang dan harus menjalani hidup dengan bergantung pada cuci darah (hemodialisa) 1,5 juta orang. Menurut Ismail, Hasanudin (2014) jumlah penderita gagal ginjal di Indonesia sekitar 150 ribu orang dan yang menjalani hemodialisa 10 ribu orang (Nastiti, 2015) Dari studi pendahuluan di ruang Hemodialisa RSUD Jombang tanggal 29 Februari 2016 dengan menggunakan kuesioner tentang Self Efficacy dan kuesioner kecemasan. Dari 10 responden mengatakan mereka 
melakukan terapi hemodialisa sesuai jadwal yang ditentukan dokter, tidak menyerah melakukan cuci darah dan menerima keadaan sakitnya sekarang. Upaya yang dilakukan petugas kesehatan di ruang Hemodialisa yaitu memberi motivasi kepada pasien agar yakin dengan terapi Hemodialisa bisa mempertahankan hidup pasien.

Seseorang yang menderita penyakit ginjal kronis tidak dapat sembuh atau pulih fungsi ginjalnya secara keseluruhan, yang bisa dilakukan hanyalah mempertahankan fungsi ginjal yang ada. Salah satu perawatannya dengan hemodialisis yang dapat mencegah kematian (Smeltzer, Suzzane C,2009). Pasien harus menjalani terapi dialysis sepanjang hidupnya (biasanya 1-3 kali seminggu) atau sampai mendapat ginjal baru melalui operasi pencangkokan ginjal (Corrigan,2011). Pasien yang menjalani dialysis mungkin mengalami kurangnya control atas aktivitas kehidupan sehari -hari dan social, kehilangan kebebasan, pensiun dini, tekanan keuangan. Hal ini dapat mengakibatkan gangguan psikologis seperti kecemasan (Tokala,2015). Cemas akan memperparah penyakit yang di rasakan. Salah satu cara untuk meredakan kecemasan adalah dengan Self Efficacy. Self Efficacy yaitu kemajuan diri pasien untuk sembuh. Faktor yang mempengaruhi Self Efficacy yaitu pengalaman keberhasilan, pengalaman orang lain, persuasi verbal dan keadaan fisiologis (Putra,2013).
Self efficacy merupakan salah satu cara meredakan kecemasan dan sebagai suatu perkiraan individu terhadap kemampuannya sendiri dalam mengatasi situasi. Seseorang yang didiagnosa GGK akan menjalani terapi hemodialisa. Pada dasarnya, setiap pasien yang mengalami penyakit akan memiliki fungsi fisik yang lebih ketika pasien memiliki keyakinan dari dalam dirinya atau memiliki kemampuan untuk melakukan perilaku tertentu. Dalam hal ini adalah dalam mengatasi rasa sakit akibat penyakit yang diderita dan melaksanakan gaya hidup sehat untuk dapat sembuh. (Putra, 2013).

Berdasarkan latar belakang diatas, peneliti merasa tertarik untuk mengangkat masalah Hubungan Self Efficacy dengan Tingkat Kecemasan Pada Pasien Gagal Ginjal Kronik yang sedang Menjalani Hemodialisa Di RSUD Jombang.

\section{METODE PENELITIAN}

Jenis penelitian ini adalah metode analitik korelasi dengan pendekatan cross sectional. Pada penelitian ini populasi sejumlah 33 responden mencakup seluruh pasien gagal ginjal kronik yang sedang menjalani hemodialisa di RSUD Jombang pertama kali - 6 bulan. Sampel sejumlah 30 responden diambil menggunakan Accidental Sampling. Variabel independen adalah self efficacy, variabel dependen Kecemasan, cara pengambilan data dengan koesioner uji statistic yang dipakai spearman's rank

\section{HASIL PENELITIAN}

Tabel 1 Distribusi frekuensi data responden penderita gagal ginjal yang menjalani hemodialisa di RSUD Jombang

\begin{tabular}{|c|c|c|c|}
\hline No. & Karakteristik Responden & $\Sigma$ (Jumlah) & Presentase $(\%)$ \\
\hline
\end{tabular}




\begin{tabular}{|c|c|c|c|}
\hline 1 & $\begin{array}{c}\text { Jenis Kelamin } \\
\text { Laki-laki } \\
\text { Perempuan }\end{array}$ & $\begin{array}{l}16 \\
14\end{array}$ & $\begin{array}{l}53,3 \\
46,7\end{array}$ \\
\hline \multirow[t]{4}{*}{2} & Usia & & \\
\hline & $45-59$ tahun & 15 & 50 \\
\hline & $60-74$ tahun & 14 & 46,7 \\
\hline & $75-90$ tahun & 1 & 3,3 \\
\hline \multirow[t]{5}{*}{3} & Pendidikan & & \\
\hline & SD & 10 & 33,3 \\
\hline & SMP & 13 & 43,3 \\
\hline & SMA & 6 & 20 \\
\hline & Perguruan Tinggi & 1 & 3,3 \\
\hline \multirow[t]{4}{*}{4} & Pekerjaan & & \\
\hline & Tidak Bekerja & 15 & 50 \\
\hline & Pedagang/ petani & 14 & 46,7 \\
\hline & PNS & 1 & 3,3 \\
\hline \multirow[t]{8}{*}{5} & Lama HD & & \\
\hline & 2 minggu & 1 & 3,3 \\
\hline & 1 bulan & 2 & 6,7 \\
\hline & 2 bulan & 6 & 20 \\
\hline & 3 bulan & 5 & 16,7 \\
\hline & 4 bulan & 6 & 20 \\
\hline & 5 bulan & 6 & 20 \\
\hline & 6 bulan & 4 & 13,3 \\
\hline
\end{tabular}

Sumber : Data primer 2016

Tabel 2. Distribusi frekuensi Self Efficacy penderita gagal ginjal kronik yang menjalani terapi hemodialisa di RSUD Jombang

\begin{tabular}{clcc}
\hline No. & \multicolumn{1}{c}{ Self Efficacy } & $\boldsymbol{\Sigma}($ Jumlah $)$ & Presentase (\%) \\
\hline 1 & Positif & 15 & 50 \\
2 & Negative & 15 & 50 \\
\hline & Total & 30 & 100 \\
\hline
\end{tabular}

Sumber : Data Primer 2016

Tabel 2. menunjukkan bahwa setengah $(50 \%)$ dari responden memiliki Self Efficacy positif sejumlah 15 orang sedangkan setengah $(50 \%)$ dari responden memiliki Self Efficacy negatif sejumlah 15 orang

Tabel 3. Distribusi frekuensi Kecemasan penderita gagal ginjal kronok yang menjalani terapi hemodialisa di RSUD Jombang

\begin{tabular}{clcc}
\hline No. & Kecemasan & $\boldsymbol{\Sigma}($ Jumlah $)$ & Presentase $(\%)$ \\
\hline 1 & Tidak cemas & 11 & 36,7 \\
2 & Ringan & 10 & 33,3 \\
3 & Sedang & 9 & 30 \\
\hline & Total & 30 & 100 \\
\hline
\end{tabular}


Tabel 3. menunjukkan bahwa hampir memiliki tingkat kecemasan setengah $(36,7 \%)$ dari responden tidak cemas sejumlah 11 orang

Tabel 4. Tabulasi silang antara Self Efficacy dengan Kecemasan pada penderita gagal ginjal kronok yang menjalani terapi hemodialisa di RSUD Jombang

\begin{tabular}{lcccccccc}
\hline \multirow{2}{*}{ Self Efficacy } & \multicolumn{9}{c}{ Kecemasan } & \multicolumn{2}{c}{ Total } \\
\cline { 2 - 8 } & \multicolumn{2}{c}{ Tidak cemas } & \multicolumn{2}{c}{ Ringan } & \multicolumn{2}{c}{ Sedang } & \multicolumn{2}{c}{} \\
\cline { 2 - 8 } & $\mathrm{f}$ & $\%$ & $\mathrm{f}$ & $\%$ & $\mathrm{f}$ & $\%$ & $\mathrm{f}$ & $\%$ \\
\hline Positif & 11 & 36,7 & 4 & 13,3 & 0 & 0 & 15 & 50 \\
Negative & 0 & 0 & 6 & 20 & 9 & 30 & 15 & 50 \\
\hline Total & 11 & 36,7 & 10 & 33,3 & 9 & 30 & 30 & 100 \\
\hline
\end{tabular}

Sumber : Data primer2016

Tabel 4 menunjukkan bahwa dari seluruh responden yaitu 30 responden setengah $(50 \%)$ yaitu dari 15 responden hampir setengahnya $(36,7 \%)$ responden dengan self efficacy positif memiliki tingkat kecemasan tidak cemas sejumlah 11 orang dan sebagian kecil (13,3\%) responden dengan self efficacy positif memiliki tingkat kecemasan ringan sejumlah 4 orang sedangkan setengah (50\%) yaitu 15 responden sebagaian kecil (20\%) dengan self efficacy negative memiliki tingkat kecemasan ringan sejumlah 6 responden dan hampir setengahnya (30\%) responden dengan self efficacy negative memiliki tingkat kecemasan sedang sejumlah 9 responden Dari data di atas dapat disimpulkan bahwa semakin positif Self efficacy yang dimiliki responden semakin berkurang kecemasannya. Hasil Uji statistic menggunakan spearman rank menunjukkan nilai koefisien korelasi $\mathrm{r}=$ 0,669 dan nilai signifikansi $\rho=0,001$ lebih kecil dari 0,05 maka H1 diterima yang berarti ada hubungan cukup antar self efficacy dengan kecemasan pada penderita gagal ginjal kronik yang sedang menjalani hemodialisa di RSUD Jombang.

\section{PEMBAHASAN}

Self Efficacy Penderita Gagal Ginjal Kronik yang Menjalani Hemodialisa di RSUD Jombang

Berdasarkan Tabel 2 dapat diketahui bahwa dari 30 responden yang menderita gagal ginjal kronik yang menjalani hemodialisa di RSUD Jombang setengah (50\%) responden memiliki Self efficacy positif sejumlah 15 orang, sedangkan setengah $(50 \%)$ responden memiliki Self Efficacy negatif sejumlah 15 orang

Self efficacy terkait dengan aspek fisiologis kesehatan: orang yang tidak memiliki self-efficacy mengalami stress dan berdampak pada kesehatan dan system imunnya. Self-efficacy juga terkait dengan potensi individu untuk berperilaku sehat, orang yang tidak yakin bahwa mereka dapat melakukan suatu perilaku yang dapat menunjang kesehatan akan cenderung enggan mencobanya (Friedman \& Schustack, 2008).

Self-efficacy diperlukan bagi penderita gagal ginjal kronik yang 
menjalani terapi hemodialisa untuk mempertahankan hidupnya. Dengan self efficacy penderita gagal ginjal kronik yang menjalani terapi hemodialisa merasa yakin jika dilakukan terapi hemodialisa dapat mempertahankan hidunya. Maka dari itu Self-efficacy perlu dipertahankan, atau mungkin ditingkatan dan dikembangkan. Hal ini terlihat dari penderita gagal ginjal kronis di ruang hemodialisa RSUD jombang bisa menerima penyakitnya dan menjalani hemodialisis sesuai jadwal yang ditentukan dokter, yang didukung setengah responden $(50 \%)$ tidak bekerja sehingga mempunyai waktu luang untuk menjalani hemodialisa

\section{Kecemasan Penderita Gagal Ginjal Kronik yang Menjalani Hemodialisa di RSUD Jombang}

Berdasarkan Tabel 3 dapat diketahui bahwa dari 30 responden yang menderita gagal ginjal kronik yang menjalani hemodialisa di RSUD Jombang hampir setengah $(36,7 \%)$ responden memiliki tingkat kecemasan tidak cemas sejumlah 11 orang

Seseorang yang menderita penyakit ginjal kronis tidak dapat sembuh atau pulih fungsi ginjalnya secara keseluruhan, yang bisa dilakukan hanyalah mempertahankan fungsi ginjal yang ada. Salah satu perawatannya dengan hemodialisis yang dapat mencegah kematian (Smeltzer, Suzzane C,2009). Pasien harus menjalani terapi dialysis sepanjang hidupnya (biasanya 1-3 kali seminggu) atau sampai mendapat ginjal baru melalui operasi pencangkokan ginjal (Corrigan,2011). Pasien yang menjalani dialysis mungkin mengalami kurangnya kontrol atas aktivitas kehidupan sehari hari dan sosial, kehilangan kebebasan, pensiun dini, tekanan keuangan. Hal ini dapat mengakibatkan gangguan psikologis seperti kecemasan (Tokala,2015). Hampir setengah $(36,7 \%)$ responden penderita gagal ginjal kronis yang menjalani hemodialisa memiliki tingkat kecemasan tidak cemas sejumlah 11 orang, hal ini dimungkinkan mereka sudah menerima penyakitnya dan mau menjalani hemodialisa secara teratur sesuai jadwal dokter yang didukung seluruh responden sudah menjalani hemodialisa lebih dari satu kali .

\section{Hubungan Self Efficacy dengan tingakat kecemasan pada pasien gagal ginjal kronik yang menjalani hemodialisa di RSUD Jombang}

Berdasarkan tabel 4 dapat diketahui bahwa dari seluruh responden yaitu 30 responden setengah $(50 \%)$ yaitu dari 15 responden hampir setengahnya $(36,7 \%)$ responden dengan self efficacy positif memiliki tingkat kecemasan tidak cemas sejumlah 11 orang dan sebagian kecil $(13,3 \%)$ responden dengan self efficacy positif memiliki tingkat kecemasan ringan sejumlah 4 orang sedangkan setengah $(50 \%)$ yaitu 15 responden sebagaian kecil $(20 \%)$ dengan self efficacy negative memiliki tingkat kecemasan ringan sejumlah 6 responden dan hampir setengahnya (30\%) responden dengan self efficacy negative memiliki tingkat kecemasan sedang sejumlah 9 responden. Dapat disimpulkan bahwa semakin positif Self efficacy yang dimiliki responden semakin berkurang kecemasannya. Salah satu cara meredakan kecemasan adalah Self efficacy. Selfefficacy dan kecemasan sangat berperan penting dalam manajemen pengelolaan pada penderita gagal ginjal kronik yang sedang menjalani hemodialisa. Self efficacy berperan penting dalam memberikan keyakinan bahwa dengan dilakukan terapi hemodialisa akan bisa mempertahankan hidup pasien (Putra,2013). Self efficacy yang positif pada penderita gagal ginjal kronik mampu menurunkan kecemasan yang dirasakan saat menjalani hemodialisa sehingga dapat meningkatkan kualitas hidupnya. 


\section{KESIMPULAN}

1. Setengah $(50 \%)$ penderita gagal ginjal kronik yang sedang menjalani hemodialisa di RSUD Jombang memiliki self efficacy positif.

2. Hampir setengahnya $(36,7 \%)$ dari responden tidak cemas.

3. Ada hubungan self efficacy dengan tingkat kecemasan pasien gagal ginjal kronik yang menjalani hemodialisa di RSUD Jombang tahun 2016.

\section{SARAN}

1. Bagi Peneliti Selanjutnya

Bagi penelitian yang menggunakan dasar penelitian yang sama, diharapkan penelitian ini dapat menjadi bahan referensi serta diharapkan untuk dilakukannya pengembangan penelitian pada faktor lain yang berhubungan dengan self efficacy ataupun Kecemasan. Selain itu disarankan agar peneliti berikutnya dapat meneliti variabel lain seperti faktor yang memengaruhi self efficacy pasien dengan penyakit akut atau pengaruh self efficacy terhadap perawatan gagal ginjal kronik yang menjalani hemodialisa.

2. Bagi Institusi Pendidikan

Diharapkan hasil penelitian ini dapat menjadi pertimbangan agar materi tentang self efficacy dimasukkan dalam materi pembelajaran untuk memberikan asuhan keperawatan pada pasien dengan penyakit kronis.Sehingga asuhan keperawatan dapat lebih aplikatif dengan berfokus kepada pasien dan bersifat komperhensif.

3. Bagi Tempat Penelitian ( Ruang Hemodialisa RSUD Jombang)

Diharapkan untuk meningkatkan pelayanan melalui konseling, informasi dan edukasi tentang penatalaksanaan gagal ginjal kronik dan dapat memberikan pengetahuan tentang self efficacy.
4. Bagi keluarga

Diharapkan dapat mendukung penerapan self efficacy pada anggota keluarga yang menderita gagal ginjal kronik yang sedang menjalani terapi hemodialisa agar yakin dirinya bisa mempertahankan hidup dengan terapi hemodialisa.

\section{DAFTAR PUSTAKA}

Corrigan, RM. 2011. The experience of the older adult with end stage renal Disease on hemodialysis. Thesis. Queen's University. Canada.

Friedman, H.S., \& Schustack, M.W. 2008.Teori Kepribadian Teori Klasik dan Riset Modern :Jilid I. Jakarta: Erlangga.

Lestari,T.2014.Kumpulan teori untuk kajian pustaka penelitian kesehatan. NuhaMedika, Yogyakarta; hal. 31-46.

Nastiti, Fietras. 2015. Tingkat Pendidikan dan Pengetahuan Gizi Terhadap Asupan Kalium Pada Penderita Gagal Ginjal Kronik yang menjalani Hemodialisa Di RSUD Sukoharjo. Tugas Akhir thesis.Universitas Muhammadiyah Surakarta.

Putra, Septiady, Suhana. 2013. Hubungan Health Locus of Control dan Self Efficacy pada Pasien Gagal Ginjal Akut yang Menjalani Hemodialisa di Rumah Sakit AL-Islam Bandung. Hal : 500-502.

Riset Kesehatan Dasar (Riskesdas) Kementerian Kesehatan RI tahun 2013.

Riset Kesehatan Dasar (Riskesdas) Kementerian Kesehatan RI tahun 2016. 
Sarafino. E.P \& Smith.T.W.2011. Health Psychology : Biopsychosocial Interactions $\left(7^{\text {th }}\right.$ ed). United States of Amerika : John Willey \& Sons Inc

Smeltzer, Suzzane C. Buku ajar keperawatan medikal bedah Brunner \& Suddarth. Ed 8. Jakarta: EGC; 2009

Tokala, Vika MN., 2015, Hubungan Self Efficacy Dengan Tingkat Kecemasan Mahasiswa Presentasi.Online (https://www.researchgate.net/publ ication/42355991_Hubungan_Anta ra_Self-

Efficacy_Dengan_Kecemasan_Ber bicara_Di_Depan_Umum_Pada Mahasiswa_Fakultas_Psikologi_U niversitas_Sumatera_Utara.,

diakses tanggal 1 Desember 2015). 